\title{
Impact of changes in the fuel injection controller settings on the power and torque performance depending on the engine speed
}

\author{
Marietta Markiewicz ${ }^{1, *}$ and Natalia Dluhunovych ${ }^{2}$ \\ ${ }^{1}$ UTP University of Science and Technology, Faculty of Mechanical Engineering, Al. prof. S. \\ Kaliskiego 7,- 85-796 Bydgoszcz \\ ${ }^{2}$ Khmelnytsky National University, Faculty of Programming Computer and Telecommunication \\ System, 11, Instytuts'ka str., Khmelnytskyi, 29016, Ukraine
}

\begin{abstract}
The internal combustion engine is the powerhouse of motor vehicles. The basic fuel used for self-ignition engine powering is diesel oil. The efficiency of an internal combustion engine depends on many factors and is defined by such parameters as power output, torque, and the engine rotational speed. The engine performance parameters can be improved by modification of the manufacturer's computer software that controls the engine operation. The study presents results of tests of a drive unit involving adjusting the fuel injection controller settings. The modifications involved increasing the fuel dose and the air charge pressure. Tests were carried out on a load bearing chassis dynamometer. The research object was a self-ignition engine with $109 \mathrm{KM}$ power and Common Rail injection system. Power and torque measurements were carried out for the engine rotational speed range up to $4000 \mathrm{rev} / \mathrm{min}$. It was found that modifications of the manufacturer's engine computer software contribute to power and torque increase for all the rotational speeds.
\end{abstract}

\section{Introduction}

The first self-ignition engine was constructed by Rudolf Diesel in 1893. It was powered by peanut oil. Not sooner than after development of petroleum refining technology diesel oil was found to be a much more universal fuel when used in self-ignition engines $[1,2]$. The twentieth century was a breakthrough in petroleum extraction and refining which made it the fastest developing branch of industry $[3,4]$. Deposits of sticky crude oil are sought by geologists and obtained through wells in a 1-kilometer deep soil, for which mining statistics are needed [5]. Advantages of fuels designed for these engines are their good lubricating properties, lower viscosity and high octane number which indicates the engine ability to self-ignite. According to PN-EN590+A1:2017-6 norm [6] diesel fuel should have specific parameters which are presented in table 1.

Table 1.Diesel oil parameters.

\begin{tabular}{|c|c|}
\hline Cetane number & 50 \\
\hline Density (w temp. $15^{\circ} \mathrm{C}$ ) & $820-845 \mathrm{~kg} / \mathrm{m}^{3}$ \\
\hline Content of aromatic carbohydrates & $\geq 11 \%$ \\
\hline Sulfur content & $\geq 10 \mathrm{mg} / \mathrm{kg}$ \\
\hline Ignition temperature & $55^{\circ} \mathrm{C}$ \\
\hline Water content & $\geq 200 \mathrm{mg} / \mathrm{kg}$ \\
\hline Viscosity (in temp. $40^{\circ} \mathrm{C}$ ) & $2-4,5 \mathrm{~mm} / \mathrm{s}$ \\
\hline
\end{tabular}

* Corresponding author: marmar000@utp.edu.p1 
Although the structure of a modern drive unit is significantly different from its prototype constructed in the XIX century, the basic function of the engine, that is, unaided fuel self-ignition has not changed so far [7]. The structure of a modern self-ignition engine enables modification of the manufacturer's computer software to improve the engine performance. There is a variety of methods to be used for the engine performance parameter improvement [8]. The most common methods involve connecting an additional device to the engine beam, the so called "power box" [9]. Another method is modification of the manufacturer's engine computer software $[10,11]$. This method involves reading the engine characteristics and uploading a new software for the fuel injection controller setting. The software can be read from the vehicle computer through a diagnostic connector OBDII, directly from the processor through BDB connector by removing the memory and reading in the programmer $[9,10]$. The manufacturer's settings are most often modified for drive units equipped with turbocharging, as they contain an electronic control unit [12].

This study aims at checking the impact of the engine computer software modifications on the torque increase depending on the drive unit rotational speed.

\section{Materials and methods}

The research object was a self-ignition engine mounted in a vehicle. The drive unit was selected due to its being frequently used in car transport, in vehicles with admissible gross vehicle weight up to $3.5 \mathrm{t}$. The engine was characterized by direct fuel injection, controlled by means of Common Rail system with electromagnetic injectors. Technical data of the drive unit are presented in table 2 .

Table 2. Technical data of a drive unit.

\begin{tabular}{|c|c|}
\hline Engine cubic capacity & $1560 \mathrm{~cm}^{3}$ \\
\hline Injection type & direct \\
\hline Engine power & $109 \mathrm{KM}$ \\
\hline Maximal torque & $240 \mathrm{Nm}$ \\
\hline Number of cylinders & 4 \\
\hline Cylinder diameter & $73 \mathrm{~mm}$ \\
\hline Piston stroke & $88,3 \mathrm{~mm}$ \\
\hline Number of valves & 16 \\
\hline Charging & Turbo compressor \\
\hline
\end{tabular}

The engine which was tested was serviceable with a drive unit used in the conditions of a city traffic. Prior to starting the measurements the drive unit was heated up to the temperature of the coolant which was about $85^{\circ} \mathrm{C}$. All the sensors and probes were connected to the vehicle (temperature sensor, pressure sensor, exhaust emission and particulate measurement probes). The structure of the drive unit used in the tests is characteristic of solutions applied in high power engines. Thanks to this, it is possible to adapt the obtained results to a wider group of engines.

The experiment was performed to determine the engine performance parameters. The tested object was placed in a chassis dynamometer equipped with an eddy current brake of Dynotech type simulating the road conditions. During the experiment the fuel injection settings were changed to acquire necessary information. Chassis dynamometer enables acquisition of data indispensable for determination of the drive unit performance characteristics such as power and torque $[13,14]$. The device was used to measure torque on the crankshaft and calculate the engine power on the basis of the torque value and the crankshaft rotational speed [15]. The measurement was affected by the air moisture, atmospheric pressure changes and the air temperature whose values were normalized. The 
results provided by the measurements were calculated into values corrected according to the applicable norm $\left(25^{\circ} \mathrm{C}\right.$ and $\left.1000 \mathrm{hPa}\right)$. A test measurement was performed to make it possible for the dynamometer to automatically determine the location of gear box location of the gear box and the final drive for the gear which would be used for performance of the proper measurement. The chassis dynamometer used in the tests consists of a suspension system with the braking unit, the engine cooling system and a control-measurement system. Figure1 shows a vehicle which was mounted on the chassis dynamometer. Specification of the chassis dynamometer used for the tests is presented in table 3.

Table 3. Specification of chassis dynamometer.

\begin{tabular}{|c|c|}
\hline maximal speed & $288 \mathrm{~km} / \mathrm{h}$ \\
\hline Maximal torque on the wheels & $1300 \mathrm{Nm}$ per one axle \\
\hline Maximal power & $900 \mathrm{HP}$ per one axle \\
\hline Maximal torque on the engine & $1000 \mathrm{Nm}$ per one axle \\
\hline brake powering & $230 \mathrm{~V} / 16 \mathrm{~A}$ \\
\hline mass & $3000 \mathrm{~kg}$ \\
\hline Length/width/height & $3800 / 4500 / 500 \mathrm{~mm}$ \\
\hline maximal/minimal & $2100 / 700 \mathrm{~mm}$ \\
\hline
\end{tabular}

Fig. 1. Vehicle mounted on a load bearing chassis dynamometer.

The tested vehicle was adjusted through modification of the engine electronic system involving changing the manufacturer's computer software of the drive unit. Introduction of changes into the fuel injection controller was supposed to discover whether and how the vehicle performance parameters undergo change. Due to the specificity of the vehicle electronic system it was necessary to remove the deck computer each time and introduce changes into the software on a special test stand which is presented in figure 2. Before introduction of modifications to the computer software, a diagnostic measurement was performed to determine the possibilities and advisability of improving the engine performance parameters.

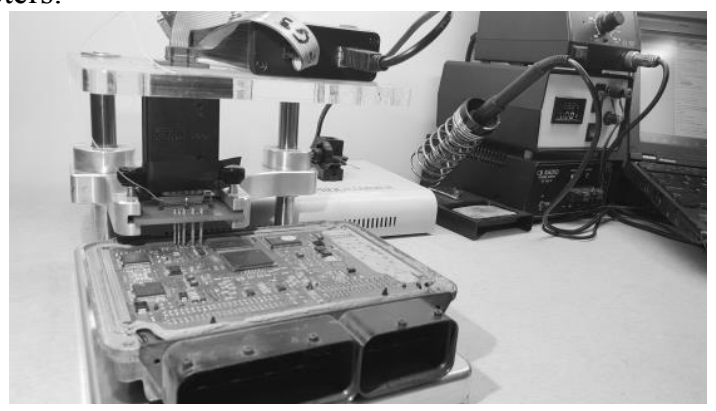

Fig. 2. Test stand used for modifications. 
Changes in the fuel injection controller settings were introduced according to a pre-set experiment plan. Modifications of the vehicle computer involved increasing the fuel doses and the amount of air supply. The tests covered five settings of the fuel injection controller which are presented in table 4 . Figure 3 shows an exemplary characteristics of fuel injection for an increased fuel dose.

Table 4. Fuel injection controller settings.

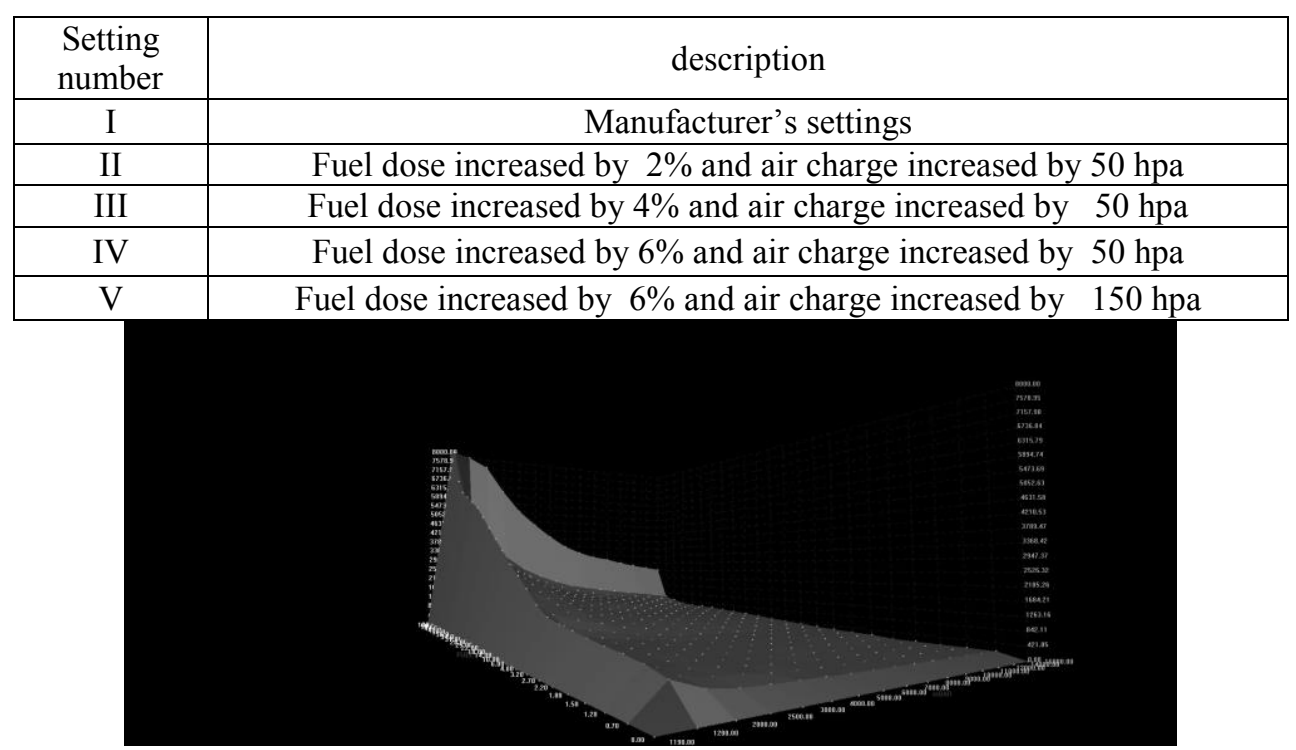

Fig. 2. Characteristics of fuel injection for an increased fuel dose.

Power and torque tests for different settings of fuel injection controller were repeated 30 times. Results of the tests were subjected to statistical analysis with the use of Statistica program.

\section{Results}

The test results have proven that for the manufacturer's settings, the maximal power reached by the drive unit was $102 \mathrm{KM}$, at $3600 \mathrm{rev} / \mathrm{min}$ and maximal torque $232 \mathrm{Nm}$, at $2400 \mathrm{rev} / \mathrm{min}$. Increasing the dose of fuel and air to be supplied to the improvement in the engine performance parameters for all rotational speeds. The differences of power test results were statistically significant and involved changes in the range from $0 \mathrm{KM}$ to 20 KM. The biggest differences were reported for rotational speeds in the range from 2900 $\mathrm{rev} / \mathrm{min}$ do $3400 \mathrm{rev} / \mathrm{min}$. For low rotational speeds $(0-2500 \mathrm{rev} / \mathrm{min})$ the differences were statistically insignificant. Increasing the fuel dose by $2 \%$ did not cause significant growth in the engine power input as compared to the drive unit standard performance parameters. No sooner than after increasing the fuel dose by $4 \%$, and the air dose by $50 \mathrm{hPa}$, the power increase was statistically significant (for $\mathrm{p}=0.05$ ). Further increasing the fuel dose did not cause a significant power increase. Increasing the air dose by $150 \mathrm{hPa}$, with a higher fuel dose $6 \%$, had also an influence on the power improvement. Setting III was found to be the best setting of the fuel injection controller (increasing the fuel dose by $4 \%$ and air load by $50 \mathrm{hPa}$ ). The diagram of power in dependence on the engine rotational speed is shown in figure 3 . 


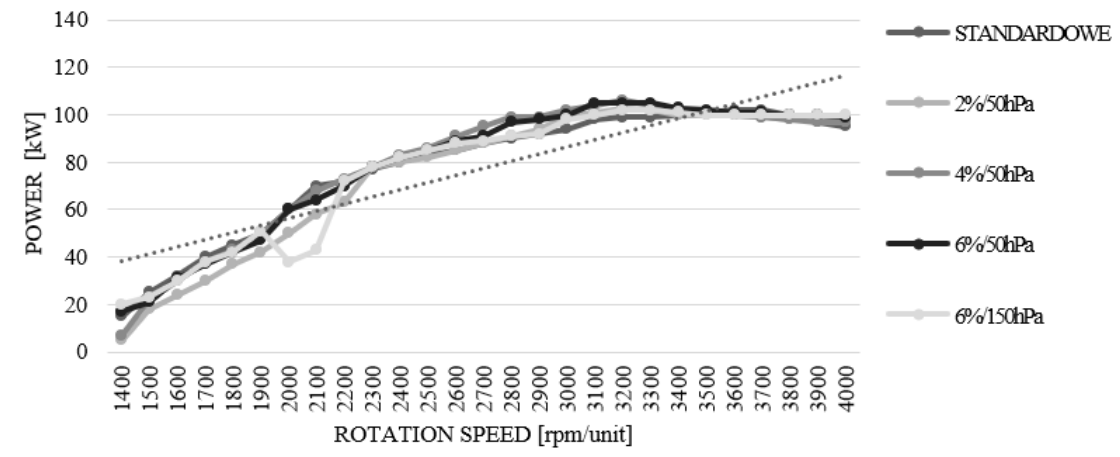

Fig. 3. Diagram of dependence between the engine power and rotational speed for the analyzed fuel injection controller setting changes.

The tests of torque yielded significant statistical differences which varied within the range from $10 \mathrm{Nm}$ to $40 \mathrm{Nm}$. The most significant differences in rotational speed was found for from $2100 \mathrm{rev} / \mathrm{min}$ to $2700 \mathrm{rev} / \mathrm{min}$. In the case of low rotational speeds $(0-2000$ $\mathrm{rev} / \mathrm{min}$ ) differences were not statistically significant. Increasing the fuel dose by $2 \%$ did not result in significant torque increase as compared to the engine standard parameters. It was the fuel dose increase by $6 \%$, for increased air charge by $50 \mathrm{hPa}$ that resulted in statistically significant (for $\mathrm{p}=0,05$ ) torque increase. Application of air chargé increased by $150 \mathrm{hP}$ for an increased fuel dose by $6 \%$, did not have a significant impact on the engine torque improvement. Setting IV (increasing the fuel dose by $6 \%$ and air charge by $50 \mathrm{hPa}$ ) ) was found to be the best fuel injection controller setting for all the analyzed rotational speeds. A diagram of torque in dependence on the engine rotational speed is presented in figure 4.

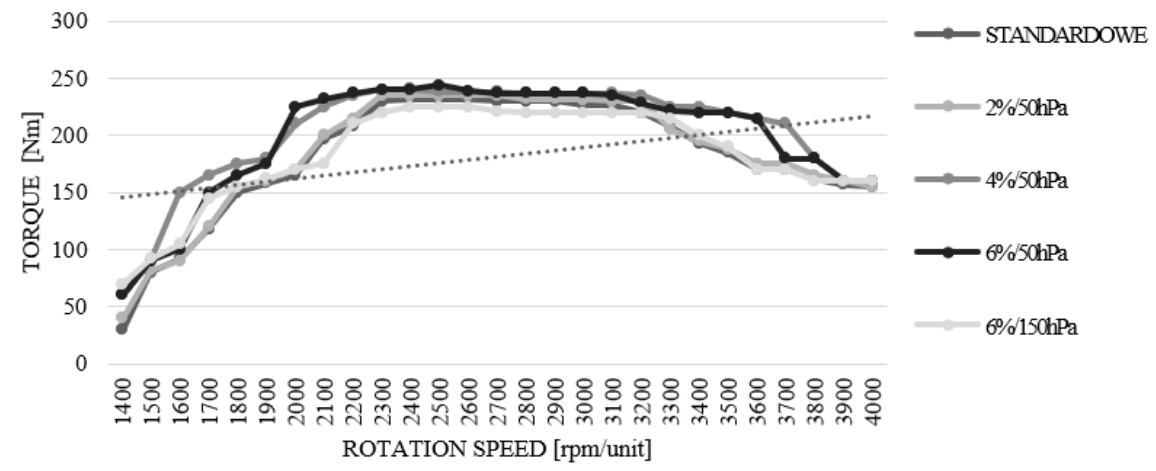

Fig. 4. A diagram of dependence of torque on rotational speed for the analyzed fuel injection controller setting changes.

The test of the engine power output and torque depending on the engine rotational speed and for variable fuel injection settings were conducted of an engine powered with pure diesel fuel (with no biocomponent additives).

\section{Conclusions}

Modifications of the fuel injection controller standard settings contribute to the engine power and torque increase which has been proven in many research centers. 
The test results have revealed that increasing the fuel supply to the engine and increasing the air charge allowed to provide the drive unit of a motor vehicle with higher power and torque.

The power increase was found to be up to $20 \mathrm{KM}$, which was recorded for all rotational speeds of the engine. The biggest differences in measurement results were observed for rotational speeds in the range of $2900-3400 \mathrm{rev} / \mathrm{min}$. Setting III was the optimal one for the fuel injection controller of the analyzed research object for power measurement (fuel dose increased by $4 \%$ and air load by $50 \mathrm{hPa}$ ). Further increasing the fuel dose and air charge caused no increase in the drive unit power.

Differences varying within the range from $10 \mathrm{Nm}$ to $40 \mathrm{Nm}$ were observed when measuring the torque for different fuel injection controller settings. The most significant differences were found for rotational speed of 2100- $2700 \mathrm{rev} / \mathrm{min}$. Setting IV (increasing the fuel dose by $6 \%$ and air load by $50 \mathrm{hPa}$ ) was found to be the optimal setting of the fuel injection controller .

The analysis of power and torque test results indicates that modifications of the drive unit computer software provided the engine with better performance parameters.

\section{References}

1. Lio H., Yu J., Xu J., Bao X., Identification of key oil refining technologies for China National Petroleum Co. (CNPC), Energy Policy, 35 (2007)

2. Castelo Branco D., Gomes G., Szklo A., Challenges and technological opportunities for the oil refining industry: A Brazilian refinery case, 38 (2010)

3. Demirbas A., Biofuels, securing the planet future Energy needs, London, Sringer Verlag Limited, 50 (2009)

4. Demirbas A., Importance of biodiesel as transportation fuel, Energy Policy, 35 (2007)

5. Pająk M., Muślewski Ł., Landowski B., Grządziela A., Fuzzy identification of the reliability state of the mine detecting ship propulsion system, Polish Maritime Research, 1 (2019)

6. PN-EN 590+A1:2017, Fuels for motor vehicles Diesel oils -Requirements and research methods (2018)

7. Mysłowski J., Development tendencies of self-ignition engines, Buses, 6 (2006)

8. Kuszewski G., Świątek D., Gutek D., Modification of a passenger computer software and its impact on the performance and operation economy of a drive unit, Buses, 12 (2017)

9. Prajkowski K., Impact of an external, so called box, module on gases composition of the ROVER 2.0 CDTI engine, Journal of Kones, 20 (2013)

10. Boguta A., Electronic modification of a self-ignition car engine performance parameters, MOTROL, 13 (2011)

11. Arcaklioglu E., Celikten I., A diesel engine performance and exhaust emissions, Applied Energy, 80 (2005)

12. Kaszkowiak J., Markiewicz M., Krzaczek P., Impact of the application of bioesters' addition to diesel oil on the course of turning moment and pwer within the scope of low rotational speed at variable settings of fuel injection, International Conference on Trends in Agricultural Engineering (2019)

13. Kołodziej E., Skrzyniowski A., Badania diagnostyczne samochodów na hamowni podwoziowej Autodyn 30, Mechanika, 10 (2012)

14. Kralik M., Jablonicky J., Nikolov M., Monitoring of NOx emission at selected diesel engine, University of Ruse „Angel Kanchev” (2015)

15. Michalski R., Gonera J., Janulin M., Wyznaczanie charakterystyki zewnętrznej ciągnika kołowego z wykorzystaniem przenośnej hamowni intercyjnej, Postępy Nauki i Techniki, 14 (2012) 